\title{
About the BCG Henderson Institute
}

The BCG Henderson Institute is the Boston Consulting Group's think tank, dedicated to exploring and developing valuable new insights from business, technology, economics, and science by embracing the powerful technology of ideas. The Institute engages leaders in provocative discussion and experimentation to expand the boundaries of business theory and practice and to translate innovative ideas from within and beyond business. 
